\title{
Underpinning Excellence In Higher Education: Exploring Self- Regulatory Skills Of High Performing Academic Students
}

\author{
Faridah Mydin K. \\ Faculty of Education \\ Universiti Kebangsaan Malaysia
}

\begin{abstract}
Learner autonomy and independence are the key to a student's success at university. Students need to be self-directed, proactive and in charge of their own learning process. Framed within the social cognitive perspective, this study sought to explore the nature and the use of self-regulatory skills employed by students in learning and extracurricular activities. This research utilised a qualitative research design. Semistructured interviews were carried out on fifteen $4^{\text {th }}$ year undergraduate students studying in one of the established research universities in Malaysia to elicit information on their self-described self-regulation skills and to examine its potential link to academic success and strong achievement in extracurricular activities. Data were analysed using thematic analysis to identify themes that emerged from the interviews. Three main self-regulation strategies were identified: goal attributed strategies, self-reflection, and self-management. The results show that high achieving students employ a range of self-regulation strategies.
\end{abstract}

Keyword: Self-regulatory skills, university, undergraduate, success, Malaysia

\section{INTRODUCTION}

The changing nature of society and the demands of a knowledge-based economy have increased the pressure on students to demonstrate a certain level of knowledge and skills that employers expect of successful students and workers. In this context, achievement of excellence at the degree level has become an important benchmark for candidates to secure employment. Smith and White (2015) described that a $1^{\text {st }}$ class degree is practically crucial nowadays for early career prospects among graduates because of tough competition in the job market. The employment market demands a candidate that is able to display competencies not only in knowledge and work skills, but also personal and interpersonal skills. The complex nature of the modern economy which demands for highly competitive graduates has resulted in a strong call for universities to produce good outputs (Naidoo, 2008). Universities are required to deliver more competitive discipline-specific degrees and provide effective learning environment that nurture students' personal and professional identities.

The knowledge, skills, and competencies that students develop when they are at university have a significant impact on their subsequent performance and achievement. Student achievement and performance has been an important field of study among researchers and practitioners as many are interested in understanding the factors that promote individual student's success at university. Consequently, the identification of factors that can help to explain individual differences in university students' success is a crucial research issue. A lot of research has mainly shown that students' belief about their capability to perform specific tasks is associated with self-regulation abilities (Cassidy, 2011; Clark, 2012; Sitzmann \& Ely, 2011). The development of self-regulation competencies in undergraduates has been recognized as an important skill needed for students to be well prepared and successful in the $21^{\text {st }}$ century 
society, and in a global economy that is driven by a knowledge-based economy (Anderman, 2011; Zimmerman \& Schunk, 2011). For university students, the ability to apply self-regulation strategies is important to maintain their cognition, positive motivation and behaviour in achieving their personal, academic and professional outcomes in various contexts and social domains. Self-regulatory processes is practically important in planning, monitoring and evaluating their learning and development. Thus, the development of self-regulation competencies has been a central concern for many higher education institutions, and it has been emphasised in curriculum and extracurricular activities.

In using an exploratory qualitative research design, this study aimed to gain richer understanding from the perspective of the participants. Existing research on self-regulation learning has often been conducted quantitatively with the focus mainly being on academic achievement. Apart from that, very little focus has been placed on exploring and understanding students' self-regulatory processes among Malaysian students in the university setting. Therefore, the focus of the present study was on the role of self-regulatory skills in the performance of academic and extracurricular activities among undergraduate students. Assessing the role of self-regulatory skills in the academic and non-academic performance may be able to provide insight regarding the possibilities for learners to use self-regulatory skills gained in one domain to progress in another. Essentially, this generic qualitative study adds to the scientific knowledge base on this topic that focuses on the experiences of high achieving students in university, particularly in terms of the contribution of self-regulation strategies to students' academic performance as well as their extra co-curricular involvement, performance and achievement.

This paper will be organised as follows: it will begin by presenting the literature on selfregulation skills with specific focus on the theory and related skills. Then, the next few sections will present the study's methodology, and the analysis of qualitative findings. Finally some conclusion are drawn, and themes of worthy additional research attention are identified.

\section{LITERATURE REVIEW}

Learning experience in higher education has constantly been documented as an important developmental context for academic and socioemotional development of a student (Wood \& Breyer, 2012). Students' experience of higher education comprises of academic studies (coursework), classroom experiences (pedagogical approach, engagement), and out-of-class experiences (participation in student organisations, sports, clubs), and these experiences directly relate to individual self-regulatory skills (Dembo \& Seli, 2008). It is all about how students manage and monitor their own planning, motivation, behaviour, and performance in various processes of learning (Boekaerts et al., Pintrich \& Zeidner, 2000; Zimmerman \& Schunk, 2001). Self-regulated competencies will prepare students for more demanding levels of education as they progress through academic careers, as well as when entering the work force, and these skills are practically important to support the lifelong learning process (Kitsantas, Winsler \& Huie, 2008).

Self-regulation, which underpins Bandura's social cognitive theory, defined as an individual's self-generated thoughts, feelings, and actions that are systematically developed to affect learning of knowledge and skills (Zimmerman, 2001). Self-regulation of learning involves learners setting goals, selecting appropriate strategies, maintaining motivation, engaging in self-monitoring, and evaluating their own academic progress (Zimmerman, 2013; Zimmerman, Schunk \& DiBenedetto, 2015). Zimmerman (2001) describes self-regulation as the degree to which students are "metacognitively, motivationally, and behaviourally active participants in their own learning processes" (p.5). Metacognitive process refers to an individual's awareness 
of his or her own thinking process and using those skills in planning, self-monitoring, evaluation and reflection. On the other hand, motivation involves a constellation of selfefficacy, values, interests, and effort with the intention of achieving specific goals. Behaviour consists of strategies, persistence, choice and actions which are proactively directed towards achieving set-goals. According to Zimmerman and Labuhn (2012), self-regulated leaners will regulate their academic behaviours and beliefs in three cyclical phases: forethought and planning phase (i.e., task analysis and setting specific task-related goals), performance monitoring phase (i.e., examination of strategies and resources used, observing progress), and self-reflection (i.e., processes occurring after learning or performance). This process is modulated by many competencies such as self-direction, adaptability, self-management, problem solving, critical thinking, communication and social skills (Anderman, 2011).

Self-regulation skills have been linked to individual competencies in several contexts (Wirth \& Leutner, 2008). Cheng (2011) mentioned that students' self-regulation ability such as students' learning motivation, goal setting, action control and learning strategies play a significant role in their learning performance (Schunk et al., 2008) There is strong evidence that self-regulation skills influence student performance and achievement in extracurricular activities (Mueller et al., 2011). Participating in extracurricular activities is an important part of the educational experience. Extracurricular activities in this context of study refers to both university-based and non-university based activities. University-based activities are those programs organised by the university, while non-university based activities are those organised by organisations outside the university such as community groups, youth organisations and others. Previous research has demonstrated that participation in extracurricular activities contributes to a student's educational and professional performance, and positively contributes to individual self-esteem, self-discipline, self-management, racial relations, and thinking skills (Fredricks, 2012). Students who demonstrate the highest level of self-regulation in the learning process would be more inclined to engage in extracurricular activities (Urban, Lewin-Bizan \& Lerner, 2010). The goal directed behaviour motivates them to optimize opportunities available to them in their environment. Therefore, the present study focused on the self-regulatory skills that students use in academic and extracurricular activities. Assessing the role of selfregulatory skills in academic and extracurricular activities of high achieving students would be able to provide insight into the inter-relatedness of this set of skills in one domain to another.

\section{METHOD}

Based on the interpretivist approach, this study aimed to understand students' construction of meaning and the perception they developed about self-regulation skills. This study took place at a medium-sized research university in Malaysia. This study was designed as a qualitative study. The exploration offered opportunities for the researcher to understand and discover issues that are rarely discussed through the voices of the participants (Seidman, 2015). In this study, purposive sampling was used for the selection of students which was conducted based on specific criteria namely: students who are in their fourth year who have obtained high academic achievement of CGPA 3.5 and above, and holds a post in any extra-curricular activities. Invitations were sent out via email to all 16 faculties. Each faculty (Head of Undergraduate Programme) was asked to nominate 5 students. Nevertheless, not all faculty responded to the email, and in the end a total of only 45 students were nominated. Each student was contacted through email with a formal invitation to participate, information about the study, and a request for scheduling an interview. Only 15 students agreed to participate in the interviews for the study. Interview sessions were conducted in campus, in a room designated by the researcher. Each interview lasted between 45 to 60 minutes. All interviews were audiotaped and transcribed verbatim. All data were analysed using an interpretative thematic approach. 


\section{RESULTS AND DISCUSSION}

The findings will present the self-regulation strategies used by the students that helped to foster their success and achievement at university. The most frequent self-regulation skills explained by the students are as follows: goal oriented attributes, self-reflection, and selfmanagement. Each theme will be discussed and presented along with relevant excerpts of the interviews quoted verbatim.

\section{Goal oriented attributes}

A variety of goal-oriented attributes were found to have a significant impact on student achievement in academic and non-academic domains. Students' goals were directed by their intrinsic and extrinsic goals. The students believed that their actions will determine their goals. Specifically, four sub-themes found under this theme: determination, self-discipline, being responsible and interest. Most of these high achievers set their goals from early on as soon as they begin their life as a student at university. For many students, the first semester of the first year is an adjustment process, where they get immersed and encultured in the culture and nature of being a university student. The students stated that they started to set goals of what they wanted to achieve in their fourth year of studies at the beginning of the second semester. For example, all the students aimed for good academic results with CGPA of at least 3.5 and above and some said they wanted to get into the Dean's List. Meanwhile in extra-curricular activities, the students already knew which clubs and organisations they wanted to participate in and aimed for high positions in these particular clubs and organisations.

Students' future oriented expectations and intentions were influenced by their intrinsic and extrinsic goals. As captured in the student interviews, determination to achieve their targeted goals was supported by ambition and willingness to work hard. As Novi said:

"I know how hard it is to grown up in a family with very little income, every day is a struggle for us. I feel privileged...for being selected to enter one of the highest rank university, I don't wanted to waste every minutes I am here. I have to work hard, I want to become the best. My ambition come true when I was nominated for vice chancellor rewards. The moments I stand in front of the crowds during the convocation is most valuable memories after all the sacrifices"

Desire and passion to be the best helped the students to self-regulate their thoughts, behaviour and emotion to work consistently on their goals. The same notion is shared by Awal who has attained awards for being one of the best students in the university through his outstanding achievement in academic (first-class honours) and also his exceptional accomplishment as a student leader and in community work. As Awal said "If I didn't set a goal to become best student in university from the beginning, I wouldn't really get as far as I am now".

Given the demands of learning at university, the students also discussed the importance of being self-disciplined and responsible in completing academic tasks. According to Amir, 'maintaining positive attitude" is considered a crucial constituent in building academic skills. Additionally, Abby shared how she managed to overcome the difficulties of the Law subject when she explained:

"I always find way to understand this subject, I will meet those who are more cleaver, smart that me, asked for their assistance, and I also always consult with my lecturer...I don't mind people said I am not smart....the most importance thing I want to understand the subject I take...I want to excel...because of depth interest in Law" 
The students agreed on the importance of trusting one's ability and capacity to work hard, and being consistent, which are seen as important qualities that would enable students to cope with the difficulties of the subjects studied.

It was also discovered that students' goal-oriented attributes were supported by students' professional attitude. These appeared in five students; four of them joined the student mobility programme while one joined the MOCK trial competition. For these five students, being open and receptive to new opportunities is an important quality that enabled them to increase their competencies. For Zaki, preparation for the MOCK competition as a team was a wonderful experience for him. Working as a team, they managed to win the award for the best MOCK trial presentation. A central element of this professional attitude involved being self-disciplined and demonstrating a readiness to make sacrifices. Additionally, for those who joined the student mobility programme as exchange students to countries like Germany and Mexico, the opportunity was perceived as a wonderful learning experience. According to Naj, being selected for the student mobility programme to Mexico was an eye opening experience for her. Through this programme, she came to understand and managed to learn about the education system of other countries, including its socio-culture, politics and others. A similar notion was shared by the others, where the student mobility programme was seen by the students as a significant learning experience, especially the importance of global minded thinking, appreciation of their own values and identities and cultural integration. In fact, student mobility is seen as an important way for universities and students to interact globally (Kehm, 2005; Marambe et al., 2012)

Goal-oriented attributes of students in the academic field also appeared in students' extracurricular participation. The ability to make connection between academic goal setting and extracurricular performance was further confirmed by the students. For example, Azli stated that he participated as a student leader in the student council because he wanted to develop his leadership talents. The desire to engage is strengthened by his motivation to be a politician in the future. Participants in this study believed that participating in ECAs did not prevent academic success. For example, for those involved as student leaders in the student council, it was found that they perceived themselves as role models as they were selected by their peers in the university's student council election. Thus, these students felt that they should become an example for others, and automatically, it is important for them to balance their achievement in both the academic and non-academic field. According to the students, apart from their interest, they joined the activities because it would increase their soft skills, making them more competent. When they have clear goals, they try their level best to perform, making them learn more about the activities and consequently performing better. The following was quoted from Hadi, in connection to his strategic planning:

"for me...join volunteerism activities is a rewarding experience for me. I don't see any harm for me to devotes time and energy to involved with the community...because I can see the benefit in future"

In this context, student orientation matches and is compatible with the opportunities provided by the university. Participation in activities driven by intrinsic and extrinsic motivation helps to drive and sustain self-regulation (Zimmerman, 2000). Both intrinsic and extrinsic motivation leads to a sense of competence and autonomy; when students are happy, they show greater engagement in activities. The above findings prove that goal oriented attributes work in tandem in both academic achievement and extracurricular performance. This was supported by the presence of strong motivational beliefs, coupled with a professional attitude, strong work ethics and commitment. In an environment that is driven by a highly competitive selection process, the importance of being aware of what it takes to excel in order to outshine 
was conveyed by the students. As Johan said "...you need extra values to market yourself in competitive job market".

\section{Self-reflection}

Self-reflection in general has a significant impact on student learning, performance and achievement. The most commonly reported self-reflection strategies include doing selfassessment and feedback.

Self-assessment is a particularly helpful strategy for students to reflect on the quality of their work and in understanding problems. According to Zif, active thinking is one of the important ingredients to find good solutions, as he stated:

"I learn about SWOT analysis in one of my medical courses.... and I realised this is very practical to applied in daily life...every time I face problem or to make a decision, I used SWOT analysis to get more reasonable solutions"

For most of the students, the learning experience at university was different from their previous learning experience. Most of the students in this study shared their feelings of anxiety, worry and uncertainty when they were in first year. As Abby shared:

"When I see my first semester results, I was really disappointed...I failed to get good results for most of my subjects, it's really a hard time for a person like me... who always aimed high. In a second semester I change my study strategies, I more engaged with my friends, join discussion and share material.... as a results I am more motivated and confident and I can see my improvement in my results..... I am happy to see the changes"

As mentioned above, student's capacity to reflect on their experience, thinking back on their actions and behaviour enabled them to monitor and evaluate the quality of their thinking and behaviour, and helped them to identify strategies to overcome their failure and weaknesses. Through the self-assessment process, the students were able to improve their understanding and skills, and it helped them to behave more professionally and more intelligently in the future.

In addition, some of the students used self-questioning to understand and solve the problems they faced. As Ling stated, every time she faced difficulties with her statistics subject, she would search for information from the internet, and find solution for her problems. According to Ling, self-questioning helped her to find an accurate formula to solve her statistics problems. Apart from the individual process, self-regulation also involved opinion and feedback from others. When students were asked about strategies and the implementation of self-reflection that promoted self-improvement in learning, the majority shared that obtaining second opinion by working with others was part of the successful strategies they employed. As Jo highlighted, "...for some academic task I will ask my friends opinion, we will work together...feedback and explanation that received from my friends makes the process much easier".

Openness to feedback is one on the main ingredients if a person wants to improve their performance. In this case, feedback, advice and suggestions from the lecturer played a significant role in the students' self-reflection process. The students commented that feedback from their lecturers are important because of their knowledge, expertise, and experience. A great deal of respect was evident in Bella's portrayal of her lecturers:

"my lecturer know my weaknesses when she read my assignment, direct feedback and comments that I received from her, make me more understand what is required to produce a good academic writing...for me it is a good learning process. 
In this context, Fong et al. (2017) surmised that the social environment and close support from peers and lecturers are recognized as contributing factors to improve the student selfreflective process. Hafiz validated this by stating:

"The important things for me to be success is, we have to be open and ready to be criticised whether it is from our peers or lecturers, don't lost focus and motivation, always remember it is part of our learning process..."

Self-reflection strategies that the students practiced in their learning process also helped the students lead a club or organisation. For example, according to Rul:

By continuously reflect upon my leadership style, I understand myself more better, I understand how to manage activities more successful, I also always get feedback from other members...we have a very good relationship"

In addition, Zack mentioned that as a university hockey player, the training process emphasised strong work ethic, through consistent amount of training and high discipline. Zack commented that regular feedback from the coaches positively influenced him by improving his thinking skills, and self-awareness. For example, he stated:

"By continuously reflect upon my training, I understand myself better, I understand my strength and weaknesses and what I can improved.... I use the same skills I learn in sports to become more successful in academic study"

Overall, the capacity to reflect on their experience and being alert to what is required to excel helped the students to develop more strategies that are constructive. One of the important characteristics of highly self-regulated learner is the ability to seek help and adapt to contextual factors (Chatzistamatiou \& Dermitzaki, 2013). The ability to reflect will help students to achieve their target and develop their talent and potential. At the same time, receiving feedback constantly is perceived important for students to develop one's performance or understanding (Hattie \& Timperley, 2007). Even though the whole idea of selfregulation is self-directed, this group of students still expected feedback to improve themselves. In this context, the quality of social relationships positively promote the development of self-regulation (Farley and Kim-Spoon 2014).

\section{Self-management}

Self-management is another key skill in self-regulation that contributes to student success. Three main themes identified which together describe the self-management skills used at university: managing time, self-learning, and self-resistance.

Time management is one of the important managerial skills that helped the students to balance their commitment in the academic and non-academic activities. The students believed that the university provides them with good opportunities for learning and for exploring knowledge outside the core curriculum. Thus, balancing all of these processes have a significant impact on the students' knowledge and professional skills development. The following are excerpts of quotes from students with regard to their strategic planning of time:

"I always give priority to importance things, early week I already planned what I would do along that week... whether it is exams, deadline for assignments, meeting, out of campus project...so I am able to meet deadline, can spend time on my extracurricular activities and also time socialise with my friends"

Apart from that, flexibility in managing time was one of the most popular methods that the students practiced when they have many deadlines to meet. As stated by Avin: 
"If my schedule very packed, I would sacrifice time that I spent on sleep, leisure with friends or outdoor activities...so I have more time to concentrate on my task"

Regardless of the heavy burden of educational activities, these students performed academically because they are multitasked, avoided unnecessary activities, stayed focused, and ultimately they believed firmly that it was their responsibility to do their best. The students mentioned that being a person who multitasked helped them to develop their talents and skills, and allowed them to experience new and different things through the extracurricular activities. As stated by Zaif, holding a post in the Student Representative Council (MPP) would demand from a student responsibility and high commitment. However, because of his passion in leadership, he managed his time smartly. As he said, "as a leader I should be an example for other students. Apart from being success in leadership, I also maintain my pointer 3.5 above. ...actually managing many things at one time make you become more independent, disciplined and matured".

The same notion was also shared by the other students who actively engaged in college activities, sports, student mobility programme, and volunteer work with the local community. In this context, maturity and effective time management helped the students to manipulate available resources and maximise their learning opportunities. The students determined the time when they needed to study alone without distraction or time when they needed to work with others. Thus, knowing how and when to work with others is an important skill.

The students also shared the importance of using various resources available that are provided by the university such as books, the internet and the library to improve their understanding of certain topics. For example, Lana said that she likes to spend time at the library, where she is able to develop deeper understanding of the subject by reading a lot of books. Accordingly, she said, the internet access provided by the university allows her to have access to various journals. As Lana explained "depending on lecturer notes only give not enough, student need to put an extra effort to do more reading to get more deeper understanding". The students indicated that working independently was a strategy that is effective. As Lily mentioned, "If I have problem with my statistics subject, I will try to solved by myself, I search for the solutions from the internets, well I don't usually ask for help, because I like to be independent". These students appear to emphasise the notion of independence in solving academic problems as a positive trait that fostered successful outcome.

Additionally, all the students admitted that collaboration-learning method makes the learning process more meaningful. The students mainly seek assistance from peers, seniors and lecturers when they are stuck in a problem. For example, as stated by Mil, "I like to collaborate with my friends, before the study group each of us will prepare one topic.... and during the study group each of us will share". When students work as a group, they will support one another. In this context, the students are not only responsible for their own learning process, but they are also responsible for the learning process of their peers (Ibrahim et al., 2015). At the same time, they also develop the ability to form interpersonal relationship and work in a team.

The following sub-themes discuss the importance of stress-resistance. The students described that high expectations, competitive environment, heavy workload, final examinations and family expectations, time pressure, and writing assignments were among the problems that caused the greatest stress for them. The following excerpt indicates the pressure that the students faced: 
"I know they are many things that I have to do, go to class, read the materials, and get a good grade... the process exhausting.... but I know I have to overcome my stress, I need to calm down"

The students experienced stress and anxiety from a variety of sources and applied different methods of coping. The students described a variety of ways in which they managed their stress, and some of these are praying, sharing their problems with friends and parents, and engaging in recreational activities. The data from the study show that self-management are positively related to student self-regulation skills. Le et al. (2005) stated that self-management is significantly related to students' academic and extracurricular performance.

\section{CONCLUSION}

This qualitative exploratory study attempted to examine the self-regulation skills practiced by high achieving students at university. Assessing the role of self-regulatory skills among high achieving students provide valuable insight into how students use self-regulatory skills not only in the academic activities but also in the extracurricular activities. The findings from this study confirmed that students who exhibited the highest level of self-regulation skills are generally more actively engaged in extracurricular activities.. Guglielmino (1994) explained that "self-directed learning describes a process in which individuals take the initiative, with or without the help of others, in diagnosing their learning needs, formulating learning goals, identifying human and material resources for learning, choosing and implementing appropriate learning strategies, and evaluating learning outcomes" (p.18). This high achieving student characteristic aligns with Biemiller and Meichenbaum (2017) who surmised that students must have self-directed learning abilities in order to become successful.

Overall, results of the study indicate that student use a range of self-regulation strategies that correlated with student academic and non-academic success. Goal oriented attributes, selfreflection and self-management are dominant strategies reported by students. Students demonstrate the capacity to use the skills they gathered in the learning process in extracurricular activities. Self-regulation strategies motivate student to work more effectively, possess better time management, displaying high level of self-efficacy and emotionally stable. Furthermore, well-developed self-regulatory skills, also nurtured by external social agents, the supportive environment and relationships. Geduld (2016), described this as the co-regulation process whereby student planning, monitoring and evaluating are supported by peers and lecturers through social interactions and continuous feedback. Given the findings presented here, it would seem important for future research to attempt to determine more precisely the relationship between self-regulation skills and the support of the learning environment. The interaction between the environment and the individual, and how it effects upon the developmental of self-regulatory skills is an area that requires further study.

\section{References}

Anderman, E. M. (2011). Educational psychology in the twenty-first century: Challenges for our community. Educational Psychologist, 46(3), 185-196.

Baumeister, R.F., \& Vohs, K.D. (2004). Handbook of Self-regulation: Research, theory, and applications. New York, NY: Guilford Press.

Biemiller, A., \& Meichenbaum, D. (2017). The nature and nurture of the self-directed learner. The Evolution of Cognitive Behavior Therapy: A Personal and Professional Journey with Don Meichenbaum, 50, 89.

Boekaerts, M., Pintrich, P. R., \& Zeidner, M. (Eds.). (2000). Handbook of self-regulation. San Diego: Academic Press. Cassidy, S. (2011). Self-regulated learning in higher education: Identifying key component processes. Studies in Higher Education, 36(8), 989-1000. 
Chatzistamatiou, M., Dermitzaki, I., \& Bagiatis, V. (2014). Self-regulatory teaching in mathematics: Relations to teachers' motivation, affect and professional commitment. European Journal of Psychology of Education, 29(2), $295-310$

Cheng E. (2011). The role of self-regulated learning in enhancing learning performance. The International Journal of Research and Review, 6(1): 1-16

Clark, I. (2012). Formative assessment: Assessment is for self-regulated learning: Educational Psychology Review, 24(2), 205-249

Dembo, M.H. \& Seji, H. (2008). Motivation and learning strategies for college success (4th ed.). New York, NY: Routledge.

Farley, J.P \& Kim-Spoon, J. (2014). The development of adolescent self-regulation: Reviewing the role of parent, peer, friend, and romantic relationships. Journal Adolescence, 37(4): 433-440.

Fredricks JA. Extracurricular participation and academic outcomes: testing the overscheduling hypothesis. Journal Youth Adolescence, 2012; 41: 295-306.

Geduld, B. (2016). Exploring differences between self-regulated learning strategies of high and low achievers in open distance learning. Africa Education Review, 13 (1), 164-181.

Gugliemino, L. M., \& Guglielmino, P. J. (1994). Practical experience with self-directed learning in business and industry human resource development. In R. Hiemstra \& R. G. Brockett (Eds.), New directions for adult and continue education: Vol. 64. Overcoming resistance to self-direction in adult learning (pp. 39-46). San Francisco, CA: Jossey-Bass.

Hattie, J., \& H. Timperley. 2007. The power of feedback. Review of Educational Research, 77: 81-112.

Ibrahim, N., Shak, M. S. Y., Mohd, T., Zaidi, A., \& Yasin, S. M. A. (2015). The Importance of Implementing Collaborative Learning in the English as a Second Language (ESL) Classroom in Malaysia. Procedia Economics and Finance, 31, 346-353.

Kehm, B. M. (2005). The Contribution of International Student Mobility to Human Development and Global Understanding. Online Submission, 2(1), 18-24

Kitsantas, A., Winsler, A. and Huie, F. (2008). Self-regulation and ability predictors of academic success during college: A predictive validity study. Journal of Advanced Academics, 20(1), 42-68.

Le, H., Casillas, A., Robbins, S. B., \& Langley, R. (2005). Motivational and skills, social, and self-management predictors of college outcomes: Constructing the Student Readiness Inventory. Educational and Psychological Measurement, 65(3), 482-508.

Marambe, K. N., Vermunt, J. D., \& Boshuizen, H. P. (2012). A cross-cultural comparison of student learning patterns in higher education. Higher Education, 64(3), 299-316.

Mueller, M. K., Phelps, E., Bowers, E. P., Agans, J. P., Urban, J. B., \& Lerner, R. M. (2011). Youth development program participation and intentional self-regulation skills: Contextual and individual bases of pathways to positive youth development. Journal of adolescence, 34(6), 1115-1125.

Naidoo, R. (2010). Global learning in a neoliberal age: Implications for development. Global inequalities and higher education: Whose interests are we serving, 66-90.

Schmeichel, V.J., \& Baumeister, R.F. (2004). Self-regulatory strength. In Handbook of Self-regulation: Research, theory, and applications (edited by R.F. Baumeister \& K.D. Vohs), pp. 84-98. New York, NY: Guilford Press

Schunk, D. H. (2008). Metacognition, self-regulation, and self-regulated learning: Research recommendations. Educational psychology review, 20(4), 463-467.

Schunk, D. H., \& Zimmerman, B. (Eds.). (2011). Handbook of self-regulation of learning and performance. Taylor \& Francis.

Seidman, I. (2015). Interviewing as Qualitative Research: A guide for researcher in education and Social Science (4th edition). Columbia University: New York

Sitzmann, T., \& Ely, K. (2011). A meta-analysis of self-regulated learning in work-related training and educational attainment: What we know and where we need to go. Psychological Bulletin, 137(3): 421-442.

Smith, E. \& White, P. (2015). What makes a successful undergraduate? The relationship between student characteristics, degree subject and academic success at university. British Educational Research Journal, 41(4): 686-708. 
Urban, J. B., Lewin-Bizan, S., \& Lerner, R. M. (2010). The role of intentional self- regulation, lower neighborhood ecological assets, and activity involvement in youth developmental outcomes. Journal of youth and adolescence, 39(7), 783-800.

Wood, L. N. and Breyer, Y.A. (2016). Success in Higher Education in Success in higher education. Transition to, within and from university. from eds Wood, L. N., Breyer, Y.A. Springer: Australia (pp 1-22)

Zimmerman, Barry J. "Self-efficacy: An essential motive to learn." Contemporary Educational Psychology 25.1 (2000): 82-91.

Zimmerman, B. J., Schunk, D. H. (2001). Reflections on theories of self-regulated learning and academic achievement. Self-regulated Learning and Academic Achievement: Theoretical Perspectives, 2, 289-307.

Zimmerman, B. J., \& Labuhn, A. S. (2012). Self-regulation of learning: Process approaches to personal development.

Zimmerman, B. J. (2013). From cognitive modeling to self-regulation: A social cognitive career path. Educational Psychologist, 48, 135-147.

Zimmerman, B. J., Schunk, D. H., \& DiBenedetto, M. K. (2015). A personal agency view of selfregulated learning: The role of goal setting. In F. Guat, H. Marsh, D. M. McInerney, \& R. G. Craven (Eds.), Self-concept, motivation, and identity: Underpinning success with research and practice (pp. 83-114). Charlotte, NC: Information Age. 